\title{
Erratum to: Reuse of tertiary municipal wastewater effluent for irrigation of Cucumis melo $\mathrm{L}$.
}

\author{
S. Martínez $\cdot$ R. Suay $\cdot$ J. Moreno $\cdot$ \\ M. L. Segura
}

Published online: 29 August 2012

(C) Springer-Verlag 2012

\section{Erratum to: Irrig Sci}

\section{DOI 10.1007/s00271-012-0342-4}

There was an inadvertent error in the address of IFAPA. The address should be "IFAPA, Andalusian Institute for Research and Training in Agriculture, Fisheries, Food and Environment, Camino San Nicolás, 1, 04745 La Mojonera, Almería, Spain".
Also, the acknowledgments should read as:

Acknowledgments Thanks to Junta de Andalucía for funding the doctoral studies of Sonia Martínez, co-author of this article, and also for granting financial aid for the research project (Project PIR-27).

The online version of the original article can be found under doi: 10.1007/s00271-012-0342-4.

S. Martínez · M. L. Segura

IFAPA, Andalusian Institute for Research and Training

in Agriculture, Fisheries, Food and Environment,

Camino San Nicolás, 1, 04745 La Mojonera, Almería, Spain

e-mail: smartnavarro@gmail.com

M. L. Segura

e-mail: marial.segura@juntadeandalucia.es

Present Address:

S. Martínez

IVIA, Instituto Valenciano de Investigaciones Agrarias, Carretera Náquera-Moncada km 4,5 Apartado Oficial,

46113 Moncada, Valencia, Spain

R. Suay ( $₫)$

IVIA, Instituto Valenciano de Investigaciones Agrarias, Carretera Náquera-Moncada km 4,5 Apartado Oficial,

46113 Moncada, Valencia, Spain

e-mail: suay_ric@gva.es

\section{J. Moreno}

Department of Applied Biology, University of Almeria,

Carretera Sacramento s/n., La Cañada de San Urbano,

04120 Almería, Spain

e-mail: jcasco@ual.es 